\title{
¿El trabajo de parto en mujeres con cesárea previa aumenta el riesgo de muerte perinatal?
}

Risk of Perinatal Death Associated with Labor After Previous Cesarean Delivery in Uncomplicated Term Pregnancies. Gordon CS, Jill P Pell, Alan D; JAMA 2002; 287:2684-2690

\author{
Objetivo \\ Evaluar si el trabajo de parto en mujeres con embarazo de térmi- \\ no y antecedentes de cesárea anterior aumenta el riesgo de muerte \\ perinatal. \\ Diseño \\ Estudio poblacional de cohorte retrospectivo. \\ Lugar \\ Maternidades de Escocia.

\section{Pacientes} \\ Todos los nacimientos institucionales $(n=313.238)$ de $37-43$ \\ semanas de edad gestacional, con feto único y en presentación \\ cefálica, ocurridos en las maternidades de Escocia entre 1992 y \\ 1997 presentes en el registro de morbilidad y en la encuesta \\ escocesa de muertes neonatales y fetales.

\section{Evaluación de Factores Pronósticos} \\ Se comparó la mortalidad perinatal en 4 grupos de mujeres con \\ embarazos de término no complicados: a) mujeres con antecedente \\ de cesárea a las que se les permitió entrar en trabajo de parto, b) \\ mujeres con antecedente de cesárea a quienes se les indicó una \\ cesárea en forma planificada, c) mujeres multíparas sin cesáreas \\ anteriores a las que no se les indicó una cesárea planificada y d) \\ mujeres nulíparas a las que no se les indicó una cesárea planifi- \\ cada. Las variables pronósticas evaluadas fueron: edad y altura \\ materna, hábito de fumar, estado socioeconómico, peso fetal, edad \\ gestacional y bajo peso al nacer.
}

\section{Medición de Resultados Principales}

Muerte perinatal vinculada al trabajo de parto (muerte fetal intraparto o muerte neonatal no causada por anomalías congénitas).

\section{Resultados Principales}

El riesgo de muerte perinatal vinculada al trabajo de parto fue 11 veces mayor en el grupo de mujeres con cesáreas anteriores que tuvieron un trabajo de parto (Odds Ratio* [OR] 11.6 IC95\%, 1.6 a 86.7) que en aquéllas a las que se les practicó una cesárea electiva.

El riesgo de muerte perinatal en las mujeres con cesáreas anteriores fue similar cuando se comparó con el grupo de nulíparas en trabajo de parto (OR 1.3 IC95\%, 0.8 a 2.1) pero fue más del doble cuando se lo comparó con mujeres multíparas en trabajo de parto (OR 2.2 IC95\%:1.3 a 3.5).

En una mujer con cesárea anterior, al entrar en trabajo de parto, aumenta el riesgo de muerte perinatal en 91\% (IC95\% 36\% a 99\%) con respecto a aquéllas que se les programa una cesárea electiva.

\section{Conclusiones}

Los resultados de la investigación muestran un riesgo significativamente mayor en las tasas de muerte perinatal para las mujeres con cesárea previa que entraron en trabajo de parto comparadas con aquéllas que se les planificó una cesárea de elección. Hay que tener en cuanta, sin embargo, que el riesgo absoluto* de muerte perinatal asociado al trabajo de parto es bajo.

\section{Comentario}

Los datos del presente estudio son datos nacionales de Escocia y provienen de una base de datos con muy buena cobertura y de alta calidad. La fuerza de la evidencia que surge del análisis de estos datos está limitada por la naturaleza observacional del estudio. Por tratarse de un estudio no aleatorizado, desconocemos si los dos grupos en comparación: "trabajo de parto" y "cesárea repetida de elección" fueron similares en variables clínicas y demográficas que pudieron influir en los resultados. Los autores no nos brindan información que nos permita saber si las mujeres que entraron al grupo cesárea electiva hubieran calificado para entrar al grupo trabajo de parto. Existe la posibilidad que las mujeres elegidas para una u otra vía de finalización del embarazo puedan diferir en forma sistemática en variables pronósticas conocidas o aún desconocidas y que ellas pudieran ser las responsables (y no la vía del parto) de las diferencias en los resultados. Si bien el efecto sobre la mortalidad perinatal fue ajustado por variables como nivel socioeconómico, edad materna, estatura, edad gestacional y peso al nacer, falta sin embargo conocer la distribución de otras variables pronósticas como ser: concurrencia a control prenatal, anestesia epidural, monitoreo electrónico fetal y complicaciones médicas y obstétricas.

Los resultados de la investigación muestran importantes diferencias en las tasas de muerte perinatal que son estadísticamente significativas (OR 11.6, IC95\% 1.6 a 86.7). Estas diferencias relativas representan pequeñas reducciones absolutas del riesgo de muerte para el grupo cesárea electiva (RRA*: 1.1 por mil IC95\%
0.16 a 9.5 por mil). Según este estudio deberían practicarse 909 (105-6250) cesáreas electivas (en mujeres con cesárea previa) para prevenir una muerte fetal o neonatal atribuible al trabajo de parto. A diferencia de este estudio, los resultados de una muy buena revisión sistemática de estudios observacionales de buena calidad' muestran diferencias relativas sensiblemente menores en los resultados de muerte perinatal (OR: 1.71 IC95\%, 1.28-2.28). Esto haría que el número de cesáreas debiera ser aún mayor para preventir una muerte.

Sin estudios aleatorizados estos efectos reportados no pueden ser confirmados. Es de destacar además, que en el presente estudio no se evaluaron resultados maternos, lo que impide hacer un balance entre riesgos y beneficios que permita hacer una recomendación sobre la mejor vía de finalización del embarazo en mujeres con cesáreas anteriores.

Conclusión del comentador: La evidencia que surge de este estudio no permite recomendar la cesárea electiva repetida para la terminación del embarazo de mujeres con cesáreas anteriores. Sin embargo, los resultados observados encienden una luz de alarma sobre el tema y estimulan a que se realicen estudios observacionales más rigurosos evaluando resultados maternos y perinatales, o mejor aún, una investigación clínica aleatorizada colaborativa que esclarezca definitivamente la incógnita.

\section{Dr. Fernando Althabe, Dra. Giselle Tomasso}

[ Centro Latinoamericano de Perinatología. CLAP.OPS-OMS. Hospital de Clínicas Piso 16. Montevideo, Uruguay ]

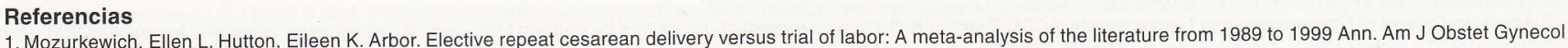
November 2000 Volume $183(5)$ 